\title{
Refractory Bile Duct Carcinoma
}

National Cancer Institute

\section{Source}

National Cancer Institute. Refractory Bile Duct Carcinoma. NCI Thesaurus. Code C153355.

Bile duct carcinoma that is resistant to treatment. 